\title{
Characterization of a Model of an Arteriovenous Fistula in the Rat
}

\section{The Effect of L-NAME}

\author{
Anthony J. Croatt, ${ }^{*}$ Joseph P. Grande, ${ }^{* \dagger}$ \\ Melissa C. Hernandez, ${ }^{*}$ Allan W. Ackerman, ${ }^{*}$ \\ Zvonimir S. Katusic, ${ }^{\ddagger}$ and Karl A. Nath* \\ From the Department of Pathology, ${ }^{\dagger}$ the Division of Nephrology \\ and Hypertension," and the Departments of Anesthesiology and \\ Molecular Pharmacology and Experimental Therapeutics, ${ }^{\neq}$Mayo \\ Clinic, Rochester, Minnesota
}

Vascular access dysfunction contributes to the mortality of patients undergoing chronic hemodialysis. The present study analyzed the changes that evolve in a femoral arteriovenous fistula in the rat. The venous segment of this model exhibited, at 1 week, activation of pro-inflammatory transcription factors and up-regulation of pro-inflammatory, proliferative, procoagulant, and profibrotic genes; and at 4 weeks, the venous segment displayed neointimal hyperplasia, smooth muscle proliferation, and thrombus formation. These changes were accompanied by endothelial (e) nitric oxide synthase (NOS) and inducible (i) NOS up-regulation. The administration of $\mathbf{N}^{\mathbf{G}}$-nitro-L-arginine methyl ester, an inhibitor of NOS activity, increased venous neointimal hyperplasia and pro-inflammatory gene expression (monocyte chemoattractant protein-1 and cytokine-induced neutrophil chemoattractant-1), increased systolic blood pressure, and decreased blood flow through the fistula. In another hypertensive model, the rat subtotal nephrectomy model, venous neointimal hyperplasia in the arteriovenous fistula was also exacerbated. We conclude that this arteriovenous fistula model recapitulates the salient features observed in dysfunctional, hemodialysis arteriovenous fistulas, and that venous neointimal hyperplasia is exacerbated when this model is superimposed in two different models of systemic hypertension. Since the uremic milieu contains increased amounts of asymmetric dimethylarginine, we speculate that such accumulation of this endogenous inhibitor of NOS, by virtue of its pressor or nitric oxide-depleting effects, or a combination thereof, may contribute to the limited longevity of arteriovenous fistulas used for hemodialysis. (Am J Pathol 2010, 176:2530-2541; DOI: 10.2353/ajpath.2010.090649)

An adequately functioning hemodialysis vascular access is essential for effective hemodialysis in the management of patients with endstage kidney disease and, not surprisingly, dysfunction of vascular accesses is a major determinant of morbidity and mortality in this patient population. $^{1-6}$ Such vascular access dysfunction and its complications commonly contribute to the hospitalization of patients on maintenance hemodialysis, and accrue, on a yearly basis, well over a billion dollars in health care costs.

The most favored vascular access for hemodialysis of patients with endstage kidney disease is an arteriovenous fistula (AVF). However, AVFs may fail either at a relatively early or a more delayed time point after which they were created. ${ }^{1-6}$ Early or primary failure of an AVF represents maturational failure of the fistula such that it can never be used for hemodialysis; this early failure may reflect either an intrinsic inability of the vascular segments to dilate and accommodate enhanced blood flow, the presence of juxta-anastomotic stenosis, or the presence of accessory veins. Late or secondary failure of an AVF occurs when a fistula loses its capacity to sustain hemodialysis because of vascular stenosis or thrombosis, or a combination of both processes. Vascular stenosis occurring in a fistula, either early or late, reflects neointimal hyperplasia, the latter arising from inflammatory and proliferative changes that narrow the vascular lumen, compromise blood flow, and predispose to thrombus formation. ${ }^{1-6}$ In light of these considerations, the central pathobiologic issues underlying dysfunction of

Supported by the National Institutes of Health grants DK 70124 and DK 47060 .

Accepted for publication January 5, 2010.

Address reprint requests to Dr. Karl A. Nath, Mayo Clinic, Guggenheim 542, 200 First St., SW, Rochester, MN 55905. E-mail: nath.karl@mayo.edu. 
AVFs thus include inadequate vascular responses, neointimal hyperplasia, and thrombogenesis.

To study the mechanisms underlying the dysfunction of AVFs, a number of models have been described both in large and small animals. While it is conceivable that studies in large animals may provide models that mimic more closely the human AVF, such studies are hampered by high costs, and the technical expertise and equipment required in undertaking such studies. This has led to the increasing popularity of models of an AVF in rodents. ${ }^{1-6}$ Such models range from a relatively simple approach such as the aorta-caval model created by the puncture of the aorta and the inferior vena cava, ${ }^{7,8}$ the tail-vein model in rodents achieved by microsurgical anastomosis, ${ }^{9}$ and by models requiring microsurgical techniques that anastomose an artery to a neighboring vein in the carotid or femoral regions. ${ }^{10-14}$

The present study examines an AVF model in the rat created by the anastomosis of the femoral artery to the femoral vein, and assesses whether such a model recapitulates the salient features observed in dysfunctional hemodialysis AVFs. In the course of these studies, marked induction of the nitric oxide synthase (NOS) system was observed in this model, and as vascular expression of NOS is relevant to vascular responses in health and disease, the significance of such expression of NOS was assessed by examining the structural and functional effects of inhibiting NOS in this model. This issue seems particularly relevant to the AVF used for maintenance hemodialysis, since such vascular accesses are placed in patients with chronic kidney disease, and chronic kidney disease is attended by the systemic accumulation of appreciable amounts of asymmetric dimethylarginine (ADMA), a potent inhibitor of NOS activity. ${ }^{15-17}$

\section{Materials and Methods}

\section{Surgical Placement of the Femoral AVF in the Rat}

All studies were approved by the Institutional Animal Care and Use Committee of the Mayo Clinic and performed in accordance with NIH guidelines. The surgical creation of a peripheral AVF for these studies was performed in Sprague Dawley rats (Harlan, Indianapolis, IN) weighing 225 to 275 grams using an end-to-side anastomosis of the femoral artery to the femoral vein. Rats were anesthetized by an intraperitoneal injection of sodium pentobarbital $(60 \mathrm{mg} / \mathrm{kg}$ ) and placed on a heated surface to maintain body temperature at $37^{\circ} \mathrm{C}$ during the procedure. The femoral vasculature was exposed by a $2-\mathrm{cm}$ incision along the left inguinal fold, and by retracting the abdominal musculature and other soft tissues. Using careful dissection with the aid of a dissecting scope (Nikon Instruments, Melville, NY, $\times 10$ to $\times 30$ magnification), the femoral artery and vein were freed from surrounding fascia and the femoral nerve. The branching vessels from the femoral artery and vein were ligated doubly with sterile $6-0$ silk suture and divided. The artery was then ligated at the distal end of its exposure, clamped with a non-traumatic aneurysm clip at the proximal end of its exposure, and transected just proximal to the ligation at a $45^{\circ}$ angle. Approximating clamps were situated on the vein, framing the site of the anastomosis, and a small longitudinal incision was made in the vein with a microsurgical knife. The lumens of both vessels were rinsed with heparinized saline and the transected end of the artery was attached to the opening in the adjacent vein with eight equidistant interrupted sutures using 10-0 monofilament nylon suture (Ethicon, Sommerville, NJ). The approximating clamps and the aneurysm clip were then removed, and arterial flow into the femoral vein was verified by visual inspection. Finally, the femoral vein was ligated just distal to the anastomosis. In a similar fashion, sham surgeries were performed on control rats, consisting of the inguinal incision and dissection of the vasculature from surrounding tissue. At time points between 1 and 4 weeks, rats were euthanized for the harvest of the vasculature of the AVF, and the femoral artery and vein from sham-operated rats.

In some studies, rats were treated with $N^{G}$-nitro-L-arginine methyl ester (L-NAME, $0.5 \mathrm{mg} / \mathrm{ml}$ in the drinking water, Sigma, St. Louis, MO) for 1 to 3 weeks to inhibit the activity of NOS; this dose and duration of administration of L-NAME have been used previously in an AVF model in the rat. ${ }^{18}$ In the present studies, L-NAME treatment was commenced 1 day before AVF or sham surgery and continued until the animals were euthanized. Systolic arterial pressure was measured in rats in some of these studies at 1 week using tail cuff plethysmography as used in our previous studies. ${ }^{19,20}$

\section{The 5/6 Subtotal Nephrectomy Model}

Studies were also performed in another model of systemic hypertension, the 5/6 subtotal nephrectomy "remnant" kidney model, the latter created just before the placement of the femoral AVF under sodium pentobarbital anesthesia. The subtotal nephrectomy model was fashioned, as previously described, by removal of the right kidney and segmental infarction of the left kidney, the latter induced by ligating branches of the left renal artery. $^{21}$

\section{Measurement of Femoral Arterial Blood Flow}

Blood flow was measured in the arterial limb of the AVF and the femoral artery of sham-operated rats using a perivascular flow probe (Transonic Systems Inc, Ithaca NY). ${ }^{22}$ Rats were anesthetized with an intraperitoneal injection of Inactin $(100 \mathrm{mg} / \mathrm{kg})$ and placed on a heated surface to maintain body temperature at $37^{\circ} \mathrm{C}$. Following exposure of the femoral vessels via an inguinal incision and dissection of the vessels from surrounding tissues, a 0.7-mm probe was placed on the arterial limb of the AVF or femoral artery in the sham-operated rat using acoustical couplant gel to ensure proper signal capture according to the manufacturer's recommendation. After a 30-minute equilibration period, flow measurements were recorded via a T200 flow meter (Transonic Systems) and 
WinDaq/Lite data acquisition software (DATAQ Instruments, Akron, $\mathrm{OH}$ ).

\section{Morphometric Studies}

Morphometric assessment of venous neointimal hyperplasia was undertaken, as previously described, to determine venous wall thickness and luminal area/venous wall cross-sectional area. ${ }^{12}$ Venous wall thickness was determined at 12 sagittal sections uniformly disposed around the venous wall, and the mean value for each vein was determined. To determine luminal area/venous wall cross-sectional area, the circumferential profiles of the lumen and external elastic lamina of the venous wall were outlined, and the respective areas so enclosed then determined; these areas were used to compute the ratio, luminal area/venous wall cross-sectional area.

\section{Electrophoretic Mobility Shift Assay for Analysis of Nuclear Factor $-\kappa B$ and Activator Protein -1}

Extraction of nuclear proteins and gel shift analysis were performed as described in our prior studies. ${ }^{23-25}$ The nuclear extract $(5 \mu \mathrm{g})$ from five femoral veins of shamoperated rats or three venous limbs of AVFs were pooled for each binding reaction. A double-stranded consensus oligonucleotide for nuclear factor (NF)- $\kappa \mathrm{B}$ or activator protein (AP)-1 (catalog nos. E329A and E320A, respectively, Promega, Madison, WI) was used to detect transcription factor binding. Bound and unbound oligonucleotide were separated on a 5\% TBE nondenaturing polyacrylamide gel (BioRad, Hercules, CA) and visualized by autoradiography. Supershift analysis was performed with a p65 rabbit polyclonal antibody (catalog no. sc-109, Santa Cruz Biotechnology Inc., Santa Cruz, CA) or a c-jun rabbit monoclonal antibody (catalog no. 9165, Cell Signaling, Danvers, MA) for $\mathrm{NF}-\kappa \mathrm{B}$ or AP-1 respectively.

\section{mRNA Expression by Quantitative Real-Time Reverse Transcription-PCR}

For analysis of gene expression, total RNA was extracted from rat venous tissue using the TRIzol method (Invitrogen, Carlsbad, CA) and further purified with an RNeasy Mini Kit (Qiagen, Valencia, CA), according to each manufacturer's protocol. Two hundred nanograms of purified total RNA were subsequently used in $40 \mu$ l reverse transcription reactions (Transcriptor First Strand cDNA Synthesis Kit, Roche Applied Science, Indianapolis, IN) using random hexamers. The resulting CDNA was used in quantitative real-time PCR analysis as in our earlier studies. ${ }^{23-25}$ Reactions were performed on an $\mathrm{ABI}$ Prism 7900HT (Applied Biosystems, Foster City, CA) using TaqMan Mastermix reagents (part no. 4309169, Applied Biosystems). Probes and primers used for quantification were obtained as assay sets for each target mRNA (TaqMan Gene Expression Assays, Applied Biosystems) and used according to the manufacturer's protocol. Parameters for quantitative PCR were as follows: 10 minutes at $95^{\circ} \mathrm{C}$, followed by 40 cycles of amplification for 15 seconds at $95^{\circ} \mathrm{C}$, and 1 minute at $60^{\circ} \mathrm{C}$. Expression of $18 \mathrm{~S}$ rRNA was used for standardization of the expression of each target gene.

\section{Western Analysis}

Western Analysis was performed as described in our previous studies. ${ }^{23-25}$ Briefly, proteins (25 to $60 \mu \mathrm{g}$ ) were separated on $10 \%$ Tris-HCl gels (BioRad) and transferred to polyvinylidene fluoride membranes. Primary antibodies for phosphorylated (p)-endothelial (e)NOS, eNOS, inducible (i)NOS (catalog nos. 612392, 610296, and 610431 respectively, BD Biosciences, San Jose, CA), EGR1 (catalog no. 4154, Cell Signaling), ETS1 (catalog no. sc55581, Santa Cruz Biotechnologies Inc.), or glyceraldehyde-3-phosphate dehydrogenase (catalog no. 2118, Cell Signaling) were used in overnight incubations at $4^{\circ} \mathrm{C}$. Horseradish peroxidase-conjugated secondary antibodies were then used and bands were visualized using an enhanced chemiluminescence method.

\section{Statistics}

Data are expressed as mean \pm SEM. The Student's $t$-test for parametric data, and the Mann-Whitney test for nonparametric data were used for comparisons between groups. Results were considered significant for $P<0.05$.

\section{Results}

\section{Examination of the Venous Segment of the AVF at One Week}

Since pro-inflammatory mediators are critically involved in mediating pathobiologic processes that contribute to dysfunction of an AVF, our initial studies examined activation of pro-inflammatory transcription factors at a relatively early time point. One week after the creation of an AVF in the rat, there was marked activation of the proinflammatory transcription factors, NF- $\kappa \mathrm{B}$ and AP-1, in the venous limb of the AVF, as shown by electrophoretic mobility shift assay (Figure 1, A-B). Other pro-inflammatory transcription factors, such as ETS1 and EGR1, as assessed by Western analysis at 1 week, were not induced (data not shown), thus indicating that a generalized up-regulation of pro-inflammatory transcription factors does not occur. This increased activation of NF- $\kappa \mathrm{B}$ and AP-1 was accompanied by markedly increased expression of pro-inflammatory, procoagulant, proliferative, and profibrotic genes (Table 1), some of which are known to be dependent on NF- $\mathrm{BB}$ and $\mathrm{AP}-1$ for their expression. Along with this upregulation of genes relevant to vascular injury, there was marked induction of eNOS and iNOS at this time point, as assessed by mRNA and protein expression (Figure 2, A-B). 
A

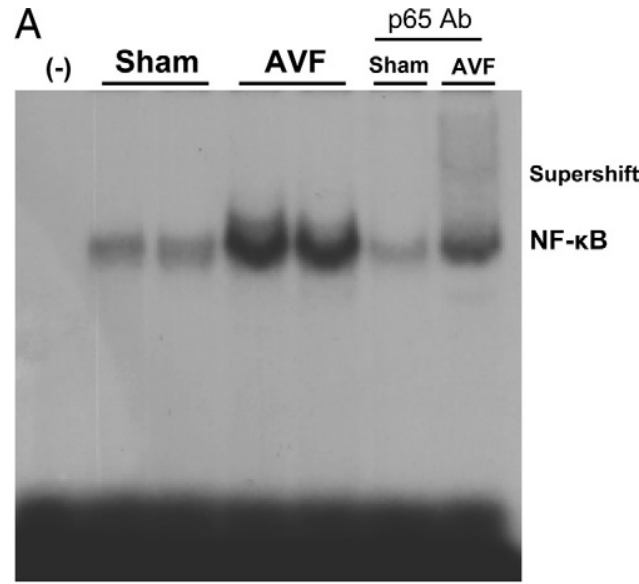

B

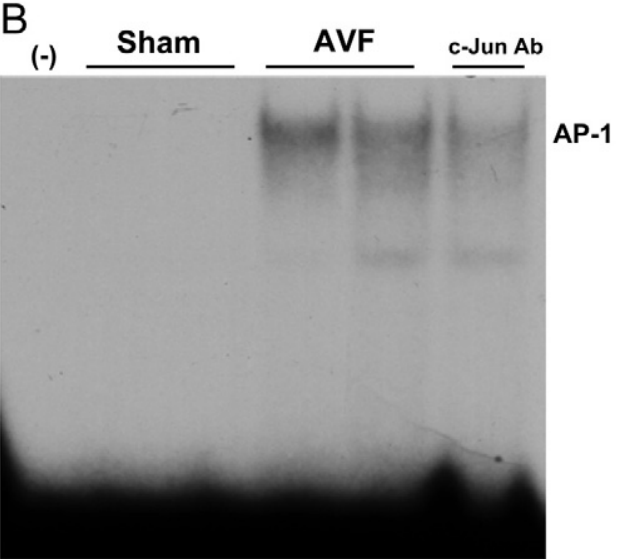

Figure 1. Electrophoretic mobility shift assay (EMSA) for NF- $\kappa \mathrm{B}$ and AP-1 binding determined in nuclear extracts from the venous limb of the rat AVF (AVF) and in femoral veins from sham-operated (Sham) rats, 1 week after AVF or sham operation. A: NF- $\kappa$ B binding in Sham and AVF venous samples. Supershift analysis was performed in venous samples using a p65 antibody. B: AP-1 binding in Sham and AVF venous samples with supershifting analysis using a c-Jun antibody. For both analyses, five Sham veins or three AVF veins were pooled in the binding reaction for each lane. The minus sign signifies a control lane that did not contain nuclear extract in the binding reaction.

\section{Examination of the Venous Segment of the AVF at Four Weeks}

Four weeks after the creation of the AVF, there was neointimal hyperplasia, smooth muscle cell proliferation, and in some instances, adherent thrombus on the venous wall (Figure 3, A-D). Induction of genes, observed at 1 week, largely persisted at 4 weeks (Table 2), and accompanied these histological changes in the vein at this time.

\section{Effect of Inhibition of NOS by L-NAME on the AVF}

Because of the marked induction of eNOS and iNOS detected at 1 week and persisting at 4 weeks, and the ensuing histological changes observed in the venous wall at 4 weeks, we examined the effect of an inhibitor of NOS in this model of an AVF. L-NAME was administered for 3 weeks, after which the AVF was evaluated by histological examination and gene expression. A prominent effect of such administration of L-NAME, and observed

Table 1. mRNA Expression in the Venous Limb of the Rat AVF (AVF) and in Veins from Sham-Operated Rats (Sham) One Week after Surgical Placement

\begin{tabular}{|c|c|c|c|c|}
\hline mRNA & Sham & AVF & $\begin{array}{c}\text { Fold } \\
\text { change }\end{array}$ & $P$ value \\
\hline MCP-1 & $6.8 \pm 0.7$ & $46.6 \pm 5.4$ & +6.9 & $<0.005$ \\
\hline IL-6 & $0.4 \pm 0.1$ & $6.2 \pm 0.9$ & +14.4 & $<0.005$ \\
\hline CINC-1 & $2.9 \pm 0.4$ & $11.1 \pm 3.0$ & +3.8 & $<0.005$ \\
\hline PAl-1 & $7.7 \pm 2.0$ & $366.0 \pm 48.0$ & +47.3 & $<0.005$ \\
\hline MMP-9 & $0.7 \pm 0.2$ & $83.5 \pm 31.3$ & +115.1 & $<0.005$ \\
\hline Osteopontin & $4.4 \pm 1.6$ & $2988.0 \pm 1043.3$ & +680.8 & $<0.005$ \\
\hline E-selectin & $1.9 \pm 0.4$ & $4.8 \pm 0.7$ & +2.5 & $<0.01$ \\
\hline P-selectin & $1.3 \pm 0.2$ & $8.5 \pm 0.9$ & +6.4 & $<0.005$ \\
\hline $\mathrm{HIF}-1 \alpha$ & $18.8 \pm 1.0$ & $38.1 \pm 2.4$ & +2.0 & $<0.005$ \\
\hline TGF- $\beta 1$ & $41.1 \pm 4.3$ & $164.6 \pm 20.0$ & +4.0 & $<0.005$ \\
\hline SDF-1 & $3.8 \pm 0.4$ & $2.5 \pm 0.3$ & -1.5 & $<0.05$ \\
\hline TLR4 & $1.0 \pm 0.1$ & $1.6 \pm 0.2$ & +1.6 & $<0.05$ \\
\hline PDGF-A & $2.3 \pm 0.15$ & $3.5 \pm 0.5$ & +1.5 & $<0.05$ \\
\hline PDGF-B & $4.9 \pm 0.5$ & $10.8 \pm 2.3$ & +2.2 & $<0.05$ \\
\hline
\end{tabular}

mRNA expression was assessed by quantitative real-time RT-PCR Values are the result of relative quantification performed against a standard curve constructed for each mRNA target, normalized for expression of $18 \mathrm{~S} \mathrm{rRNA}$, and expressed in arbitrary units.

$$
n=8 \text { in each group. }
$$

on gross inspection of the AVF, involved the venous and arterial limbs of the AVF; in rats with an AVF and treated with L-NAME, the venous limb appeared dilated while the arterial limb of the AVF appeared thin and constricted, as compared with the respective limbs of the AVF in rats maintained on standard drinking water (Figure 4, A and B). Histological examination revealed that the venous limb of the AVF in L-NAME-treated rats exhibited increased neointimal hyperplasia, as compared with the venous limb of the AVF in rats maintained on standard

A

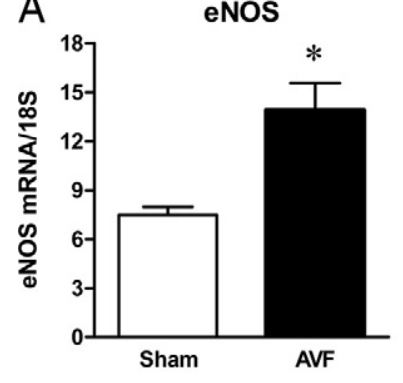

B

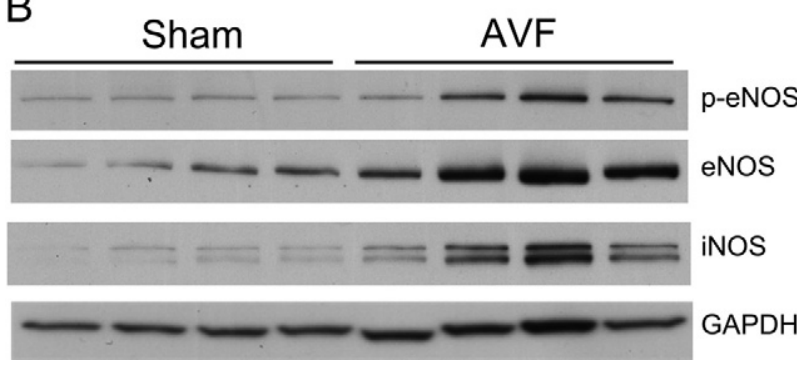

Figure 2. Expression of eNOS and iNOS MRNA and protein in the venous limb of the rat AVF (AVF) and in femoral veins from sham-operated (Sham) rats, 1 week after AVF or sham operation. A: Expression of eNOS and iNOS mRNA in Sham and AVF veins as measured by quantitative real-time reverse transcription-PCR and corrected for $18 \mathrm{~S}$ rRNA expression. $n=8$ in all groups ${ }^{*} P<0.05$. B: Western analysis for the expression of $\mathrm{p}$-eNOS, eNOS, and iNOS protein in Sham and AVF veins. Each lane represents a venous sample obtained from one rat in that group. Equivalency of loading was assessed by immunoblotting for glyceraldehyde-3-phosphate dehydrogenase. 

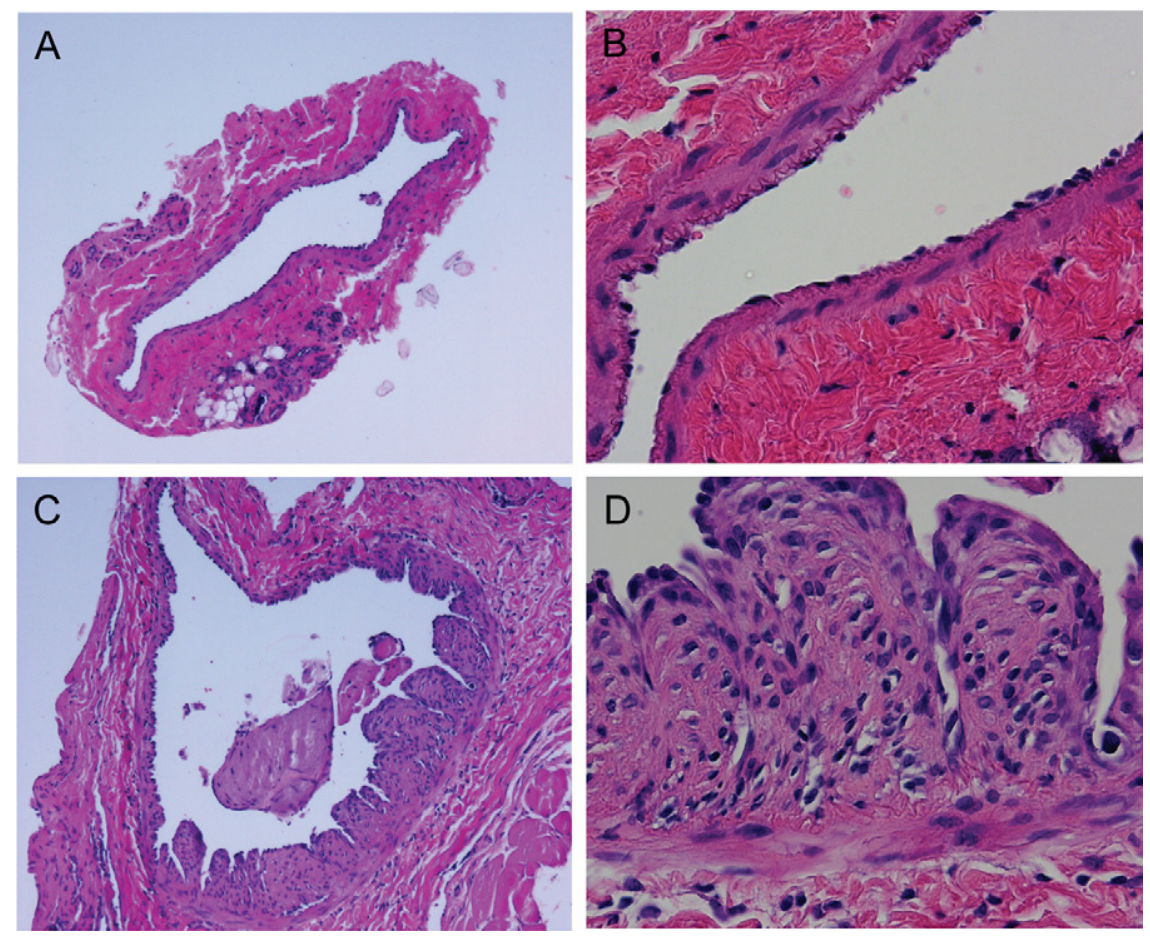

Figure 3. Histological examination of the venous limb of the rat AVF (AVF) and femoral veins from sham-operated (Sham) rats, 4 weeks after AVF or sham operation. A and B: Low power $(\mathbf{A}, \times 100)$ and high power $(\mathbf{B}, \times 400)$ views of the histological appearance of the Sham femoral vein. C and D: Low power $(\mathbf{C}, \times 100)$ and high power $(\mathbf{D}, \times 400)$ views of the histological appearance of the venous limb of the rat AVF. The AVF vein at this time point exhibits marked venous neointima formation with papillary projections into the lumen, leukocytic infiltration within the hyperplastic neointima, and the presence of luminal thrombi. All sections were stained with H\&E.

drinking water (Figure 5, A and B). Morphometric studies demonstrate that the venous limb of the AVF in L-NAMEtreated rats as compared with the venous limb of the AVF in rats maintained on standard drinking water exhibited markedly increased venous wall thickness $(62.3 \pm 11.9$ vs. $121.1 \pm 15.0 \mu \mathrm{m}, P<0.05, n=8$ and $n=7$ respectively) and decreased luminal area/venous wall area $(0.57 \pm 0.07$ vs. $0.33 \pm 0.04, P<0.05, n=8$ and $n=7$ respectively). The arterial limb of the AVF in rats on standard drinking water exhibited mildly increased cellularity, and in L-NAME-treated rats, the arterial limb of the AVF displayed focal areas of hyperplasia and hyalinosis, the latter likely reflecting focal loss of smooth muscle cells in

Table 2. mRNA Expression in the Venous Limb of the Rat AVF (AVF) and in Veins from Sham-Operated Rats (Sham) Four Weeks after Surgical Placement

\begin{tabular}{lcccc}
\hline \multicolumn{1}{c}{ mRNA } & Sham & AVF & $\begin{array}{c}\text { Fold } \\
\text { change }\end{array}$ & $P$ value \\
\hline MCP-1 & $2.5 \pm 0.8$ & $39.4 \pm 17.4$ & +15.6 & $<0.005$ \\
IL-6 & $3.9 \pm 0.7$ & $66.1 \pm 12.7$ & +17.1 & $<0.005$ \\
CINC-1 & $7.6 \pm 1.3$ & $32.3 \pm 7.4$ & +4.2 & $<0.005$ \\
PAI-1 & $3.5 \pm 0.9$ & $124.1 \pm 15.3$ & +35.0 & $<0.005$ \\
MMP-9 & $0.8 \pm 0.6$ & $36.6 \pm 13.5$ & +43.8 & $<0.005$ \\
Osteopontin & $2.2 \pm 1.0$ & $99.1 \pm 11.6$ & +45.1 & $<0.005$ \\
E-selectin & $2.9 \pm 0.8$ & $12.3 \pm 1.6$ & +4.2 & $<0.005$ \\
P-selectin & $27.9 \pm 14.0$ & $14.5 \pm 2.1$ & -1.9 & $<0.005$ \\
HIF-1 $\alpha$ & $8.5 \pm 0.9$ & $17.6 \pm 1.3$ & +2.1 & $<0.005$ \\
TGF- $\beta 1$ & $4.7 \pm 0.9$ & $20.1 \pm 1.7$ & +4.2 & $<0.005$ \\
eNOS & $2.9 \pm 0.4$ & $5.5 \pm 0.7$ & +1.9 & $<0.005$ \\
iNOS & $10.7 \pm 1.6$ & $62.9 \pm 13.7$ & +5.9 & $<0.005$ \\
SDF-1 & $7.1 \pm 1.6$ & $5.7 \pm 0.6$ & - & NS \\
TLR4 & $8.7 \pm 2.1$ & $11.7 \pm 1.3$ & - & NS \\
\hline
\end{tabular}

mRNA expression was assessed by quantitative real-time RT-PCR. Values are the result of relative quantification performed against a standard curve constructed for each mRNA target, normalized for expression of $18 \mathrm{~S}$ rRNA, and expressed in arbitrary units.

$n=8$ for the Sham group and $n=10$ for the AVF group. the media of the arterial limb (Figure 5, C and D). L-NAME did not induce histological changes in the vein or artery of the Sham-AVF.

Along with this exacerbation of these histological changes in the venous limb, there was further upregulation of such genes as monocyte chemoattractant protein (MCP)-1 and cytokine-induced neutrophil chemoattractant (CINC) -1 (the rat homologue of interleukin [IL]-8) in the venous limb of the AVF following treatment with $L$ NAME (Figure 6, A and B). In the venous limb in rats with an AVF, the administration of L-NAME led to a 2.5-fold increase in IL-6 mRNA (34 \pm 4 vs. $85 \pm 29, P=\mathrm{NS}, n=$ 7 in both groups in this and subsequent analyses), a 1.5-fold increase in osteopontin mRNA (394 \pm 89 vs. $578 \pm 96, P=N S)$, neither of which achieved statistical significance, and quite comparable levels of expression of transforming growth factor $\beta 1$ ( $114 \pm 21$ vs. $109 \pm 15$, $P=\mathrm{NS}$ ) and plasminogen activator inhibitor-1 (856 \pm 153 vs. $900 \pm 134, P=$ NS).

The adverse effects observed on the venous segment of the AVF attendant on the administration of L-NAME may reflect either a direct effect of inhibiting NOS in the venous segment or an indirect effect resulting from the systemic and local hemodynamic effects of L-NAME. To assess the systemic hemodynamic effects of L-NAME, we measured systolic blood pressure. As shown in Figure 7 , systolic blood pressure in rats with the AVF was significantly increased following the administration of L-NAME for 1 week, albeit less so as compared with the increase in systolic blood pressure observed following the administration of L-NAME in sham-operated rats; indeed, the increase in the systolic blood pressure induced by L-NAME in rats with the AVF was approximately half of the increment observed in sham-operated rats (68 vs. $35 \mathrm{mmHg}, P<0.05)$. 

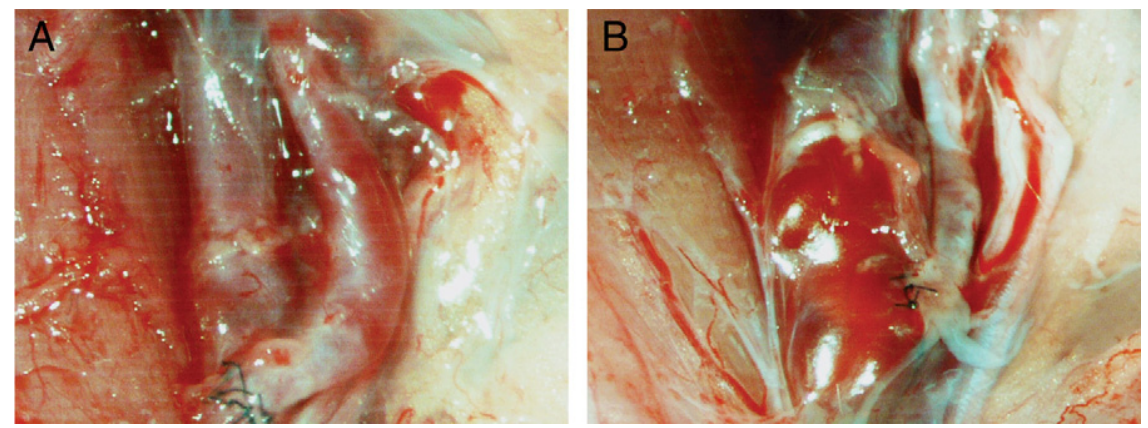

Figure 4. Appearances of the AVF in rats maintained on standard drinking water or water containing L-NAME, 3 weeks after the creation of the AVF. A: Arterial and venous limbs of an AVF 3 weeks after the creation of the AVF in a rat maintained on standard drinking water. B: Arterial and venous limbs of an AVF 3 weeks after the creation of the AVF in a rat drinking water containing L-NAME $(0.5 \mathrm{mg} / \mathrm{ml})$. As shown in panel $\mathbf{A}$, the AVF in the rat maintained on standard drinking water has both arterial and venous dilatation (compared with sham-operated femoral vessels, not shown). In contrast, the AVF from the L-NAME-treated rat, shown in panel $\mathbf{B}$ exhibits a thin, constricted arterial segment and a dilated venous segment as compared with respective segments of the AVF in a rat maintained on standard drinking water.

To assess the local hemodynamic effects of L-NAME, we examined the expression of eNOS and iNOS in the femoral artery in the AVF, and the effect of L-NAME on femoral artery blood flow in the AVF. As demonstrated in Figure 8, eNOS and iNOS were markedly induced in the arterial limb of the AVF in vehicle-treated rats in studies undertaken 1 week after the creation of the fistula, and such expression was accompanied by increased arterial blood flow in these rats (Figure 9); inhibition of NOS by L-NAME blunted this rise in arterial blood flow in the AVF.

\section{Effect of the Hypertensive Subtotal Nephrectomy Model on the Arteriovenous Fistula}

To examine the effect of systemic hypertension on the AVF, we used a model of systemic hypertension induced by $5 / 6$ subtotal nephrectomy, as this model of systemic hypertension is accompanied by chronic kidney disease and uremia, the latter representing the setting in which an AVF is created for hemodialysis. When studied at 3 weeks after subtotal nephrectomy, the serum creatinine in rats subjected to subtotal nephrectomy and AVF was significantly higher as compared with rats subjected to sham-subtotal nephrectomy and AVF $(0.43 \pm 0.03$ vs. $1.47 \pm 0.24 \mathrm{mg} / \mathrm{dl}, P<0.05, n=7$ and $n=10$ respectively; mean serum creatinine in sham-subtotal nephrectomy/sham-AVF $=0.38 \pm 0.04 \mathrm{mg} / \mathrm{dl}, n=5$ ). In this protocol using the subtotal nephrectomy model, the profile of systolic blood pressures paralleled that observed in the L-NAME study and, importantly, robust systemic hypertension was induced in rats with the AVF (Figure 10 and compare with Figure 7). Neointimal hyperplasia in the venous limb of the AVF was increased in rats which concomitantly underwent subtotal nephrectomy (Figure $11, B$ versus A). Cellular hyperplasia in the arterial limb of the AVF was also increased in rats that concomitantly underwent subtotal nephrectomy (Figure 11, D versus C). In rats with a sham-AVF, subtotal nephrectomy did not induce neointimal hyperplasia in the venous limb, but led to mildly increased cellularity in the arterial limb (data not shown).
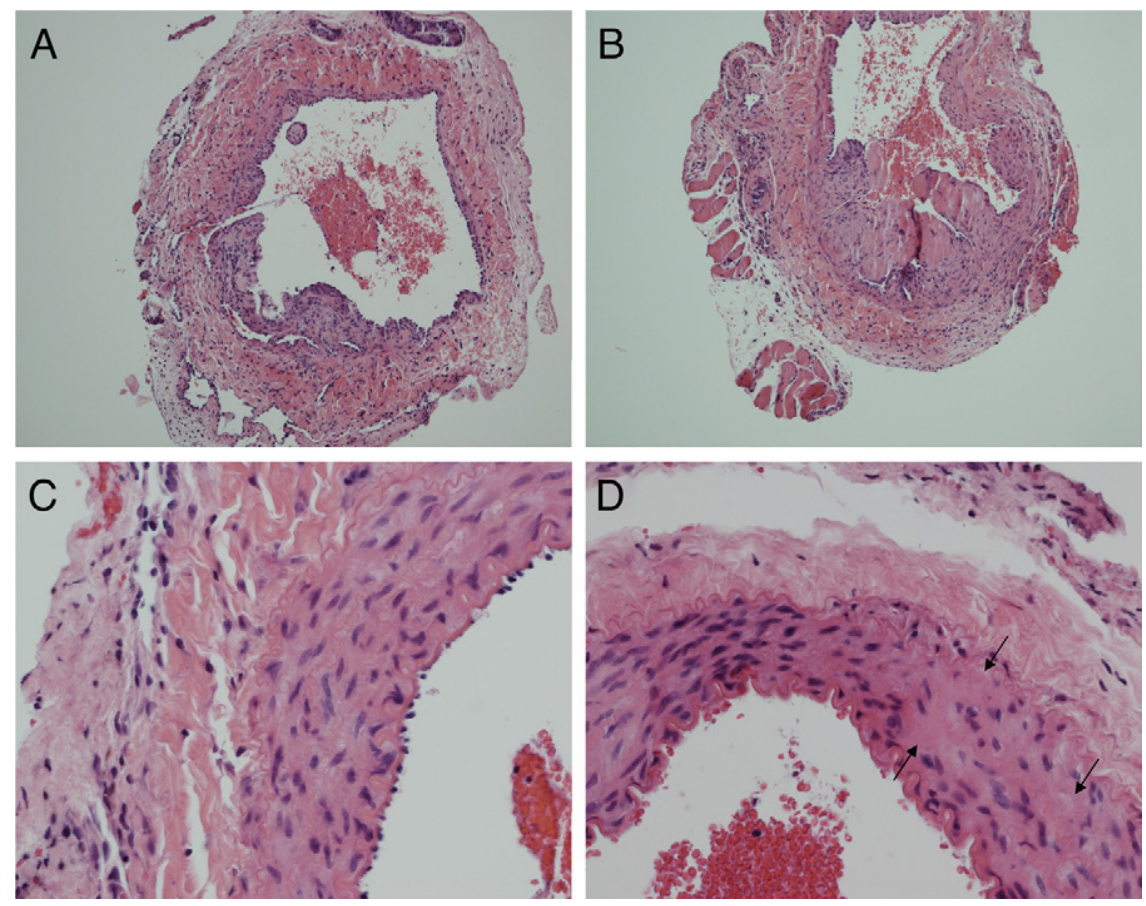

Figure 5. Histological appearances of the venous and arterial limbs of the AVF in rats maintained on standard drinking water or water containing L-NAME, 3 weeks after the creation of the AVF. A: Venous limb of an AVF 3 weeks after the creation of the AVF in a rat maintained on standard drinking water $(\times 100)$. B: Venous limb of an AVF 3 weeks after the creation of the AVF in a rat maintained on water containing L-NAME $(0.5 \mathrm{mg} / \mathrm{ml})(\times 100)$. C: Arterial limb of an AVF 3 weeks after the creation of the AVF in a rat maintained on standard drinking water $(\times 400)$ D: Arterial limb of an AVF 3 weeks after the creation of the AVF in a rat maintained on water containing L-NAME $(0.5 \mathrm{mg} / \mathrm{ml})(\times 400)$. The administration of L-NAME for 3 weeks led to increased neointimal hyperplasia in the venous limb (B vs. A). In the arterial limb, the administration of L-NAME led to foci of hyalinosis (marked by arrows), reflecting focal loss of smooth muscle cells in the media of the artery (D vs. C). All sections were stained with H\&E. 


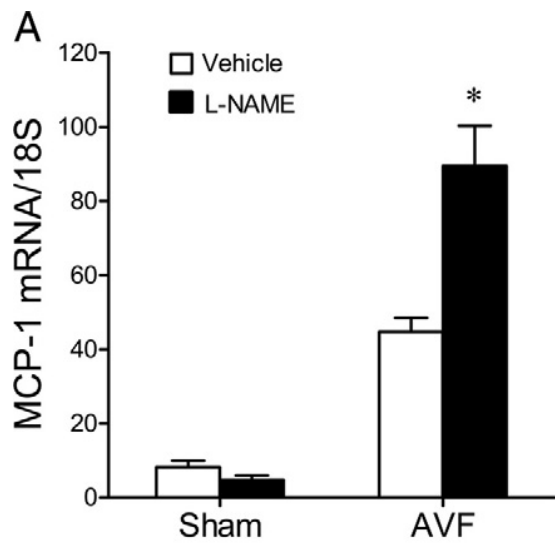

B

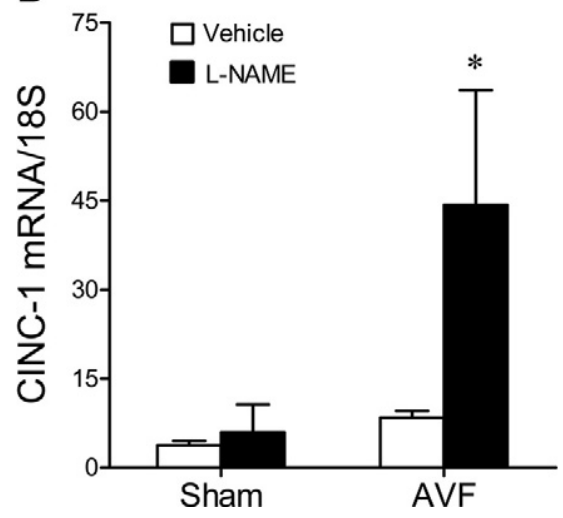

Figure 6. Expression of MCP-1 and CINC-1 mRNA in the venous limb of the AVF (AVF) and the femoral vein of sham-operated rats (Sham) in rats maintained on standard drinking water (Vehicle) or water containing L-NAME $(0.5 \mathrm{mg} / \mathrm{ml})$, 3 weeks after AVF or sham operation. MCP-1 (A) and CINC-1 (B) mRNA expression was measured by quantitative real-time reverse transcription-PCR and corrected for $18 \mathrm{~S}$ rRNA expression. $n=5$ for each of the Sham groups and $n=7$ for each of the AVF groups. ${ }^{*} P<0.05$ vs vehicle-treated AVF group.

\section{Discussion}

One week after the creation of the AVF, the venous segment demonstrated strong activation of pro-inflammatory transcription factors such as NF- $\kappa$ B and AP-1. Accompanying the activation of these transcription factors was

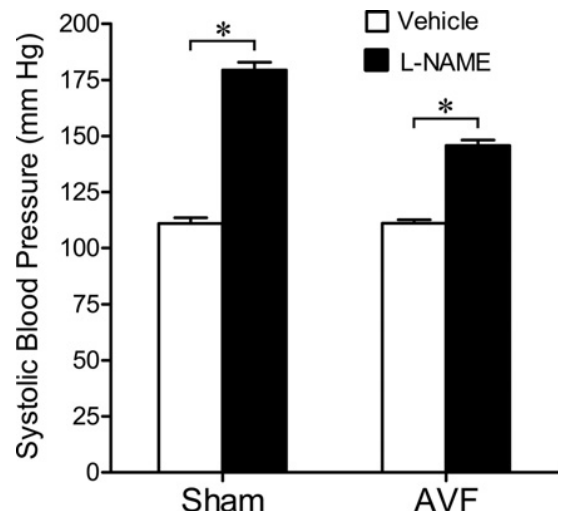

Figure 7. Systolic blood pressure in rats maintained on standard drinking water (Vehicle) or water containing L-NAME $(0.5 \mathrm{mg} / \mathrm{ml}), 1$ week after creation of an AVF (AVF) or sham operation (Sham). $n=6$ and $n=7$ in the vehicle-treated and L-NAME-treated Sham groups respectively, and $n=8$ and $n=9$ in the vehicle-treated and L-NAME-treated AVF groups respectively. ${ }^{*} P<0.05$.

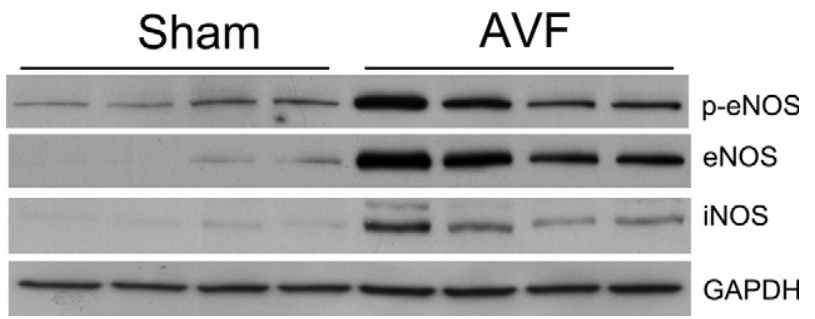

Figure 8. Western analysis of p-eNOS, eNOS, and iNOS protein expression in the arterial segment of the AVF (AVF) and the femoral artery in the sham-operated (Sham) rat, 1 week after AVF or sham operation. Each lane represents an arterial sample obtained from one rat in that group. Equivalency of loading was assessed by immunoblotting for glyceraldehyde-3phosphate dehydrogenase.

marked induction of a large number of pro-inflammatory and vasculopathic genes, several of which are dependent on these transcription factors for their expression, the latter including MCP-1, IL-6, CINC-1, plasminogen activator inhibitor-1, and matrix metalloproteinase-9. The induction of these genes observed at 1 week was largely maintained at 4 weeks, at which time point the venous segment exhibited prominent neointimal hyperplasia, smooth muscle cell proliferation, and in some instances, adherent thrombus on the venous wall. These findings thus recapitulate the pathobiologic changes that contribute to dysfunction and failure of AVFs used for maintenance hemodialysis in patients with end-stage kidney disease. ${ }^{1-6,26-32}$ Similar histological features have been described in recent studies of the venous segment of the rat femoral AVF model created by microsurgical anastomosis. ${ }^{11,14}$ These histological findings and the accompanying marked induction of genes incriminated in vascular access dysfunction (for example, MCP-1, IL-6, transforming growth factor- $\beta 1$, plasminogen activator inhibitor-1, and matrix metalloproteinase9 ), in aggregate, thus demonstrate that this model is a faithful one by which to study the pathophysiologic mechanisms underlying dysfunction of hemodialysis AVFs, and to examine strategies that may extend the longevity of these AVFs.

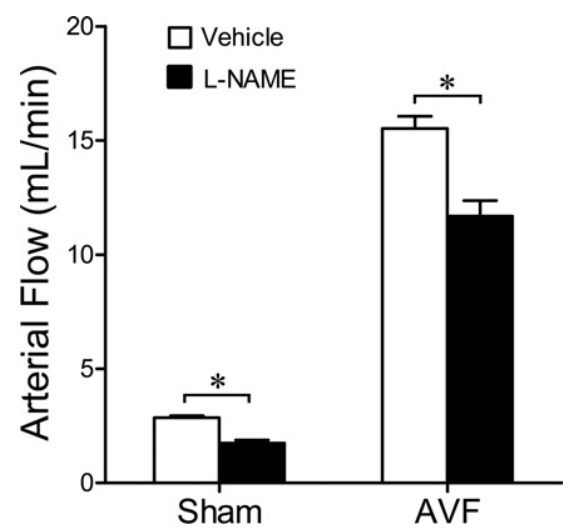

Figure 9. Femoral arterial flow as measured by flow probe in rats maintained on standard drinking water (Vehicle) or water containing L-NAME $(0.5$ $\mathrm{mg} / \mathrm{ml}$ ), 1 week after creation of an AVF (AVF) or sham operation (Sham). $n=5$ in each of the Sham groups, and $n=6$ and $n=8$ in the vehicle-treated and L-NAME-treated AVF groups respectively. ${ }^{*} P<0.05$. 


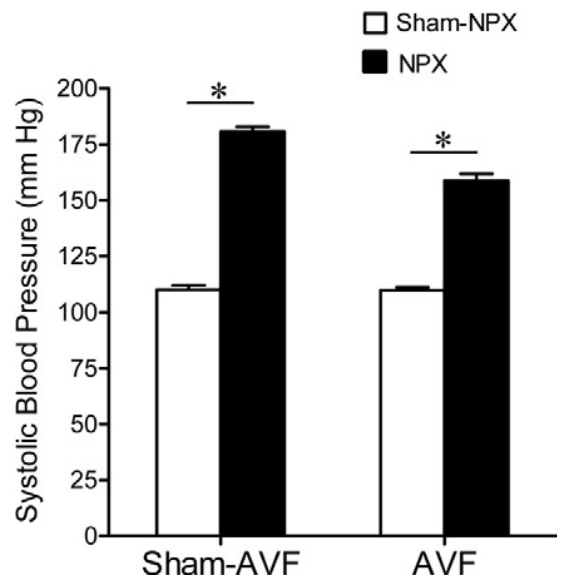

Figure 10. Systolic blood pressure in rats subjected to the creation of an AVF or Sham-AVF, and which also underwent either subtotal nephrectomy (NPX) or Sham-NPX. $n=6$ and $n=10$ in the Sham-AVF/Sham-NPX and ShamAVF/NPX groups, and $n=8$ and $n=10$ in the AVF/Sham-NPX and AVF/NPX groups respectively. ${ }^{*} P<0.05$.

A system that was markedly up-regulated, early as well as late, in the venous segment of this AVF model and as measured by gene and protein expression, involved the isoforms of NOS, eNOS, and iNOS, both of which require activation of $\mathrm{NF}-\kappa \mathrm{B}$ for the induction of their respective genes. $^{33-35}$ To determine the functional significance of such induction of NOS, the effect of L-NAME, an inhibitor of NOS, was assessed in this model of an AVF. Such inhibition led to an exaggeration of the histological changes observed in the venous limb along with the up-regulation of pro-inflammatory genes such as MCP-1 and $\mathrm{CINC}-1$, the latter representing the rat homologue of human IL-8. Thus the net effect of inhibiting NOS activity arising from eNOS and iNOS, both of which are upregulated in this model, is an exacerbation of the histological changes observed in the AVF. The pathobiologic significance of the L-NAME-induced effects on MCP-1 and $\mathrm{CINC}-1$ stems from the fact that MCP-1 and IL-8 are among the most important chemokines incriminated in the initiation and/or propagation of vascular injury. ${ }^{36-38}$ Interestingly, $\mathrm{MCP}-1$ and $\mathrm{CINC}-1$ are genes that both require activation of $\mathrm{NF}-\kappa \mathrm{B}$ for their induction. Nitric oxide is known to exert feedback inhibition on the activation of $\mathrm{NF}-\kappa \mathrm{B} .^{33,34}$ It is possible that the administration of $\mathrm{L}$ NAME, by inhibiting NOS activity reduces the ambient concentration of nitric oxide in the vasculature, thereby releasing $\mathrm{NF}-\kappa \mathrm{B}$ from feedback inhibition by nitric oxide; in turn, this augments the induction of NF- $\mathrm{BB}-$ dependent genes such as MCP-1 and CINC-1.

Nitric oxide arising from eNOS is uniformly considered a signaling molecule that preserves the function and vitality of the vasculature. ${ }^{33,34}$ Such beneficial effects of nitric oxide derived from eNOS involve vasorelaxation, inhibition of leukocytic adhesion to the endothelium, maintenance of the anticoagulant nature of the endothelium, and inhibition of proliferation and migration of smooth muscle cells; all of these properties restrain processes that drive neointimal hyperplasia, the latter representing one of the principal mechanisms that contribute to the dysfunction of AVFs. To the extent that L-NAME inhibits generation of nitric oxide from eNOS, L-NAME would, accordingly, be expected to have deleterious effects on the venous segment. Administration of L-NAME also inhibits the generation of nitric oxide from iNOS, the latter, unlike eNOS, exerting contrasting effects in models of vascular injury. ${ }^{39}$ For example, using an approach based on iNOS $^{-1-}$ mice, induction of iNOS consistently exerts adverse effects in models of atherosclerosis as shown by the ApoE knockout model. ${ }^{39}$ However, in models of vascular injury that are predominantly characterized by neointima formation and fibroproliferative changes, studies based on NOS $^{-1-}$ mice demonstrate that iNOS, more
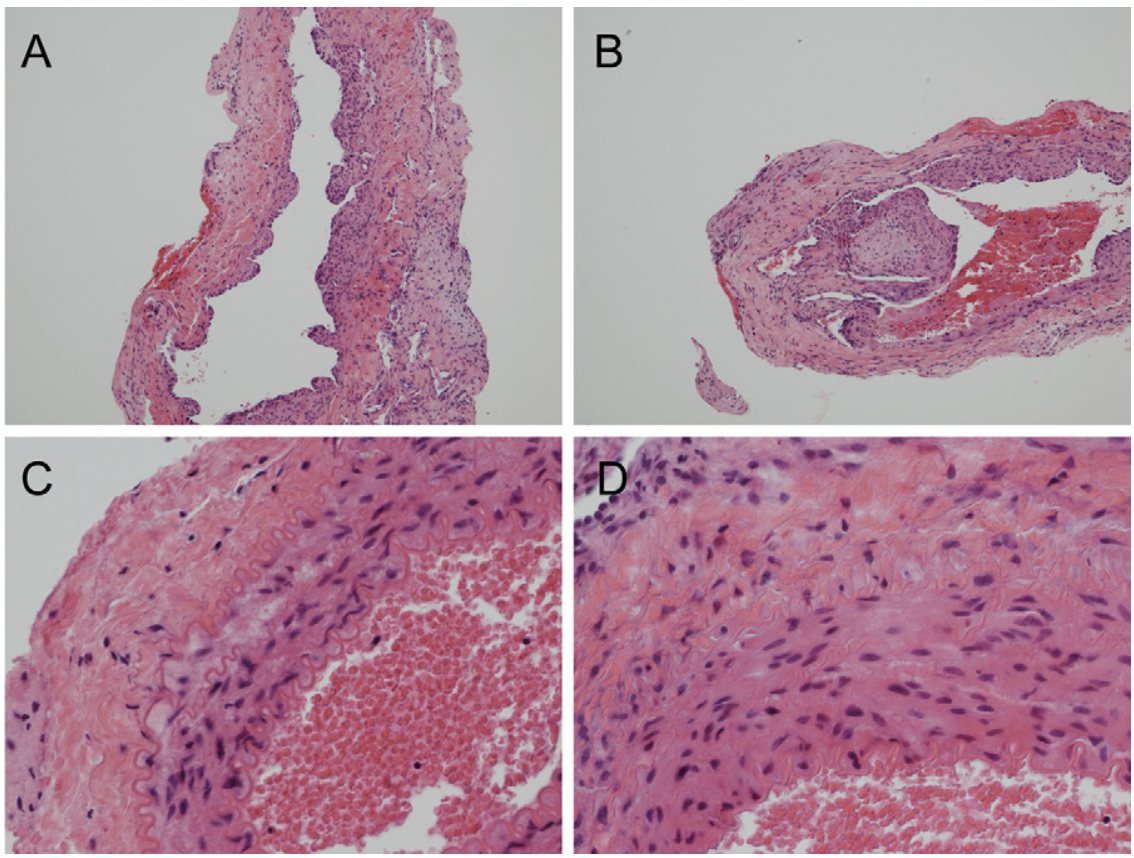

Figure 11. Histological appearances of the venous and arterial limbs of the AVF in rats that also underwent either subtotal nephrectomy (NPX) or Sham-NPX. A: Venous limb of an AVF 3 weeks after the creation of the AVF in a rat that also underwent Sham-NPX $(\times 100)$. B: Venous limb of an AVF 3 weeks after the creation of the AVF in a rat that also underwent NPX $(\times 100)$. C: Arterial limb of an AVF 3 weeks after the creation of the AVF in a rat that also underwent ShamNPX $(\times 400)$. D: Arterial limb of an AVF 3 weeks after the creation of the AVF in a rat that also underwent NPX $(\times 400)$. Neointimal hyperplasia in the venous limb of an AVF was increased in rats that also underwent NPX (B vs. A). Cellular hyperplasia in the arterial limb of an AVF was increased in rats that also underwent NPX (D vs. C). All sections were stained with H\&E. 
commonly, exerts a protective effect in such models. ${ }^{39}$ Particularly relevant to these considerations and our current findings are studies demonstrating that the up-regulation of iNOS by gene delivery techniques not only reduces vascular injury in a number of settings, but also reduces inflammation, cell proliferation, and neointima formation in venous segments interposed in arteries. ${ }^{40,41}$ Extrapolating from these observations in the literature, and our present findings, the administration of L-NAME in this vascular injury model may be broadly interpreted in either one of two ways: it is possible that induction of iNOS in the venous segment of the AVF is a protective response, and thus the administration of L-NAME worsens histological injury by inhibiting NOS activity arising from both isoforms; alternatively, induction of iNOS is an injurious, maladaptive response, and the exacerbatory effect of inhibiting NOS activity from eNOS overrides the beneficial effects of inhibiting NOS activity arising from iNOS. Delineating the specific contribution of either isoform may be approached by the imposition of an AVF in $\mathrm{eNOS}^{-1-}$ and $\mathrm{iNOS}^{-1-}$ mice, or the examination of the effect of specific inhibitors of iNOS on the AVF, analyses that are beyond the scope of the present study.

The administration of L-NAME exerted a pressor effect in sham-operated rats and rats with the AVF. While some $50 \%$ lower than that observed in sham-operated rats, the increment in systolic blood pressure following the administration of L-NAME to rats with the AVF was substantial. Given the established vasculopathic effects of systemic hypertension, these pressor effects of L-NAME most likely represent an important pathogenetic mechanism underlying the exacerbation of venous neointimal hyperplasia in the AVF in rats treated with L-NAME.

To further address the effect of systemic hypertension on the AVF, we imposed the AVF in the hypertensive subtotal nephrectomy model of chronic kidney disease, the latter representing the setting in which the AVF is created in humans. In this protocol using the subtotal nephrectomy model, the profile of systolic blood pressures paralleled that observed in the L-NAME study and, importantly, robust systemic hypertension was induced in rats with the AVF. However, other aspects besides systemic hypertension may contribute to the exacerbation of venous neointimal hyperplasia when the AVF is created in subtotally nephrectomized rats, including, for example, the effects of uremia. It is difficult to examine the isolated effect of systemic hypertension in available models without introducing some other possible mechanism and/or explanation. For example, systemic hypertension induced by angiotensin II is accompanied by increased generation of superoxide anion, the latter capable of consuming nitric oxide; deoxycorticosterone acetate-salt is associated not only with increased generation of superoxide anion, but also salt and water expansion and elevated mineralocorticoid levels; the Dahl and SHR hypertensive rat strains are genetically altered models of systemic hypertension. Such specific and additional features of these models of systemic hypertension, including the consumption of nitric oxide by superoxide anion, may be relevant and contribute to the pathogenesis of venous neointimal hyperplasia. Indeed, in the remnant kidney model, plasma levels of ADMA are increased, and this endogenous inhibitor of NOS may contribute, along with systemic hypertension, to the exacerbation of venous neointimal hyperplasia in the AVF when it is created in this setting. ${ }^{42}$

That venous neointimal hyperplasia in the AVF was increased when systemic hypertension was concomitantly induced either by subtotal nephrectomy or the administration of L-NAME leads us to emphasize the following. First, the adverse effects of L-NAME on the venous limb of the AVF reflect, either singly or in combination, the vasculopathic consequences of systemic hypertension and reduction in nitric oxide in the venous vasculature. Second, the finding that venous neointimal hyperplasia was increased in two different hypertensive models calls attention to the pathogenetic significance of systemic hypertension in the setting of end-stage kidney disease. Systemic hypertension is widely recognized for its adverse effects on cardiovascular disease and mortality in the uremic milieu. However, the adverse effects of systemic hypertension on the AVF have been insufficiently or hardly emphasized. Our findings underscore the pathogenetic significance of systemic hypertension on the venous vasculature in the AVF, and that effective control of systemic hypertension may not only lessen the risk for cardiovascular disease in end-stage kidney disease, but could also promote the longevity of the AVF. Interestingly, the histological appearance of the arterial segment of the AVF in the L-NAME-treated rat differed from that observed in the rat also subjected to subtotal nephrectomy, the latter, like the L-NAME-treated rat with an AVF, exhibiting robust systemic hypertension. Thus systemic hypertension may not be the sole explanation for the histological changes in the arterial segment of the AVF in L-NAME-treated rats.

The adverse effects on the venous segment of the AVF resulting from inhibition of NOS may also reflect an adverse "downstream" effect originating from the arterial segment of the AVF. Like the venous segment, the arterial segment exhibited marked induction of eNOS and iNOS, and such induction accompanied the augmentation in arterial blood flow in the AVF. An adaptive increment in arterial flow is a fundamental requirement in achieving a functional fistula. ${ }^{3,5,6}$ Such increased blood flow increases shear stress on the vessel wall, and increased shear stress exerts an inhibitory effect on neointima formation. ${ }^{43,44}$ Inhibition of NOS activity by L-NAME decreased the blood flow through the fistula, and it is conceivable that the attendant diminution in venous blood flow may decrease shear stress on the venous wall and thereby promote neointimal hyperplasia.

The induction of eNOS we have observed in the present study is consistent with prior studies by us and others examining the expression of this NOS isoform in arteries experiencing increased blood flow. ${ }^{45}$ The functional significance of such expression of eNOS is underscored by prior studies demonstrating that $\mathrm{eNOS}^{-1-}$ mice, as compared with eNOS ${ }^{+/+}$mice, exhibit a blunted increase in blood flow and arterial diameter following the creation of an AVF. ${ }^{46}$ Our observations regarding the reduced arterial flow through the fistula following the 
administration of an inhibitor of NOS is consistent with similar findings in an AVF model in the rat ${ }^{18}$ and rabbit ${ }^{47}$ but not in the baboon. ${ }^{48}$

Hemodialysis AVFs are created in patients with chronic kidney disease, the latter commonly attended by the accumulation and persistence in plasma of an endogenous inhibitor of NOS, ADMA, ${ }^{15-17}$ and systemic hypertension. The pathobiologic significance of this endogenous inhibitor of NOS in chronic kidney disease is underscored by the observation that ADMA is not only a biomarker for cardiovascular disease in chronic kidney disease, but may also contribute to systemic hypertension and cardiovascular disease in uremia, and to pathogenetic processes that drive progressive chronic kidney disease. ${ }^{15-17}$ Moreover, endothelial cells exposed to ADMA in vitro exhibit multiple features of a mesenchymal phenotype, ${ }^{49}$ and such endothelial-mesenchymal transition may be relevant to pathobiologic processes such as neointimal hyperplasia that develop in an AVF. In light of these observations and our findings obtained in rats with an AVF treated with L-NAME, we speculate that dysfunction and eventual failure of an AVF in humans on maintenance dialysis, may reflect, at least in part, the adverse effects of chronic inhibition of NOS occasioned by ADMA accumulating in chronic kidney disease. This speculation is supported by the following clinical observations. Histological analyses of the AVF in humans on maintenance hemodialysis demonstrate not only neointimal hyperplasia in the venous segment, ${ }^{31,50}$ but also cellular hyperplasia and apoptosis in the arterial segment ${ }^{51}$; our findings that the arterial segment in the AVF in L-NAME-treated rats exhibited foci of cellular hyperplasia and foci of hyalinosis, the latter likely reflecting cellular dropout, are congruent with these latter clinical observations. Interestingly, cellular hyperplasia and apoptosis in the arterial segment of the AVF in patients on maintenance hemodialysis correlate, independently, with stenosis of the arterial segment in the AVF. ${ }^{51}$ Finally, as shown in recent studies, in hemodialysis patients undergoing angioplasty of stenotic AVFs, higher plasma levels of ADMA are strongly predictive of the risk for restenosis. ${ }^{52}$

The femoral AVF model in the rat, as described in the present and recent studies, ${ }^{11,14,53}$ complements other rodent models used to study AVF failure. For example, the murine AVF model recapitulates the salient features of dysfunctional and failing human AVFs, ${ }^{10}$ and when created in genetically altered mice, allows the interrogation of the functional significance of specific genes; this murine model was recently used in the examination of the pathobiologic significance of heme oxygenase- $1^{12}$ and osteopontin in an AVF, ${ }^{13}$ and the therapeutic efficacy of bone morphogenetic protein 7 in this murine model when created in mice with chronic kidney disease. ${ }^{13}$ As compared with the femoral AVF in the rat, the murine model is, technically, a more demanding model, and yields markedly less vascular tissue. The aorto-caval model in the rat exhibits venous inflammatory gene expression and neointimal hyperplasia, and represents an easy-to-perform model based on needle-puncture of these central vessels. ${ }^{7,8}$ Venous neointimal hyperplasia also occurs in an AVF created in the vessels in the rat tail, and given the superficial location of the AVF, this model may be used to examine the effect of therapeutic strategies locally applied to the AVF. ${ }^{9}$

We also wish to point out that the femoral AVF model used in the present studies differs from the model used in prior studies that examined the pathogenesis of venous hypertension and insufficiency. ${ }^{54}$ In these latter studies, following the creation of the femoral AVF, the femoral vein above the AVF and the superficial epigastric vein were occluded by ligatures, and among the attendant effects of these combined experimental maneuvers were lower extremity edema and striking fibrosis in the femoral vein. The current study used a femoral AVF model without concomitant occlusion of the femoral vein above the AVF or occlusion of the superficial epigastric venous system, and did not lead to lower extremity edema or venous fibrosis.

In summary, our present findings demonstrate that this model of an AVF in the rat displays histological features observed in failing human hemodialysis AVFs, and that such histological features in this model are antedated by a robust inflammatory response. This response includes early activation of pro-inflammatory transcription factors, NF- $\kappa \mathrm{B}$ and AP-1, transcription factors known to be activated in endothelial cells by shear stress. ${ }^{33-35,43,44}$ It is tempting to speculate that activation of these transcription factors represents a maladaptive response to hemodynamic stress in the venous segment of an AVF since this response sets the stage for ensuing inflammation and neointimal hyperplasia. The significance of hemodynamic stress in this model is underscored by the fact that systemic hypertension, as imposed by two different models, exacerbated venous neointimal hyperplasia in the AVF; the adverse effects of systemic hypertension on the Iongevity of AVFs merits further investigation. The marked induction of NOS in the AVF may exert a beneficial and countervailing effect in this model since the inhibition of NOS activity and accompanying hypertension, attendant on the administration of L-NAME, heightened neointimal hyperplasia in the venous segment of the AVF. Finally, our findings lead us to offer the speculation that as ADMA accumulates in uremia, the attendant inhibition of NOS, either by its pressor or nitric oxide-depleting effect, or a combination thereof, may contribute to the finite functionality of AVFs used for maintenance hemodialysis.

\section{Acknowledgment}

We thank Mrs. Tammy Engel for secretarial expertise.

\section{References}

1. Agarwal A, Segal MS: Intimal exuberance: veins in jeopardy. Am J Pathol 2003, 162:1759-1761

2. Allon M: Current management of vascular access. Clin J Am Soc Nephrol 2007, 2:786-800

3. Dixon BS: Why don't fistulas mature? Kidney Int 2006, 70:1413-1422

4. Kanwar YS: Functional duality of progenitor cells influxing into arteriovenous fistula during its neoangiogenesis. Am J Physiol Renal Physiol 2007, 293:F468-F469 
5. Roy-Chaudhury P, Lee TC: Vascular stenosis: biology and interventions. Curr Opin Nephrol Hypertens 2007, 16:516-522

6. Roy-Chaudhury P, Spergel LM, Besarab A, Asif A, Ravani P: Biology of arteriovenous fistula failure. J Nephrol 2007, 20:150-163

7. Nath KA, Kanakiriya SK, Grande JP, Croatt AJ, Katusic ZS: Increased venous proinflammatory gene expression and intimal hyperplasia in an aorto-caval fistula model in the rat. Am J Pathol 2003, 162:2079-2090

8. Caplice NM, Wang S, Tracz M, Croatt AJ, Grande JP, Katusic ZS, Nath KA: Neoangiogenesis and the presence of progenitor cells in the venous limb of an arteriovenous fistula in the rat. Am J Physiol Renal Physiol 2007, 293:F470-F475

9. Lin T, Horsfield C, Robson MG: Arteriovenous fistula in the rat tail: a new model of hemodialysis access dysfunction. Kidney Int 2008, 74:528-531

10. Castier Y, Lehoux S, Hu Y, Foteinos G, Tedgui A, Xu Q: Characterization of neointima lesions associated with arteriovenous fistulas in a mouse model. Kidney Int 2006, 70:315-320

11. Chan CY, Chen YS, Ma MC, Chen CF: Remodeling of experimental arteriovenous fistula with increased matrix metalloproteinase expression in rats. J Vasc Surg 2007, 45:804-811

12. Juncos JP, Tracz MJ, Croatt AJ, Grande JP, Ackerman AW, Katusic ZS, Nath KA: Genetic deficiency of heme oxygenase- 1 impairs functionality and form of an arteriovenous fistula in the mouse. Kidney Int 2008, 74:47-51

13. Kokubo $T$, Ishikawa N, Uchida H. Chasnoff SE, Xie X, Mathew S, Hruska KA, Choi ET: CKD accelerates development of neointimal hyperplasia in arteriovenous fistulas. J Am Soc Nephrol 2009 20:1236-1245

14. Langer S, Heiss C, Paulus N, Bektas N, Mommertz G, Rowinska Z, Westenfeld R, Jacobs MJ, Fries M, Koeppel TA: Functional and structural response of arterialized femoral veins in a rodent AV fistula model. Nephrol Dial Transplant 2009, 24:2201-2206

15. Baylis C: Nitric oxide deficiency in chronic kidney disease. Am J Physiol Renal Physiol 2008, 294:F1-F9

16. Kielstein JT, Zoccali C: Asymmetric dimethylarginine: a novel marker of risk and a potential target for therapy in chronic kidney disease. Curr Opin Nephrol Hypertens 2008, 17:609-615

17. Stenvinkel P, Carrero JJ, Axelsson J, Lindholm B, Heimburger O, Massy Z: Emerging biomarkers for evaluating cardiovascular risk in the chronic kidney disease patient: how do new pieces fit into the uremic puzzle? Clin J Am Soc Nephrol 2008, 3:505-521

18. Guzman RJ, Abe K, Zarins CK: Flow-induced arterial enlargement is inhibited by suppression of nitric oxide synthase activity in vivo. Surgery 1997, 122:273-279; discussion 279-280

19. Haugen EN, Croatt AJ, Nath KA: Angiotensin II induces renal oxidan stress in vivo and heme oxygenase-1 in vivo and in vitro. Kidney Int 2000, 58:144-152

20. Nath KA, d'Uscio LV, Juncos JP, Croatt AJ, Manriquez MC, Pittock ST, Katusic ZS: An analysis of the DOCA-salt model of hypertension in HO-1-/- mice and the Gunn rat. Am J Physiol Heart Circ Physiol 2007, 293:H333-H342

21. Nath KA, Chmielewski DH, Hostetter TH: Regulatory role of prostanoids in glomerular microcirculation of remnant nephrons. Am J Physiol 1987, 252:F829-F837

22. Heinemann A, Wachter $\mathrm{CH}$, Peskar BA, Holzer P: Dilatation by angiotensin II of the rat femoral arterial bed in vivo via pressure/flowinduced release of nitric oxide and prostaglandins. $\mathrm{Br} \mathrm{J}$ Pharmacol 1997, 122:975-984

23. Pittock ST, Norby SM, Grande JP, Croatt AJ, Bren GD, Badley AD, Caplice NM, Griffin MD, Nath KA: MCP-1 is up-regulated in unstressed and stressed $\mathrm{HO}-1$ knockout mice: pathophysiologic correlates. Kidney Int 2005, 68:611-622

24. Tracz MJ, Juncos JP, Grande JP, Croatt AJ, Ackerman AW, Katusic ZS, Nath KA: Induction of heme oxygenase- 1 is a beneficial response in a murine model of venous thrombosis. Am J Pathol 2008, 173:1882-1890

25. Tracz MJ, Juncos JP, Grande JP, Croatt AJ, Ackerman AW, Rajagopalan G, Knutson KL, Badley AD, Griffin MD, Alam J, Nath KA: Renal hemodynamic, inflammatory, and apoptotic responses to lipopolysaccharide in HO-1-/- mice. Am J Pathol 2007, 170:1820-1830

26. Chang CJ, Ko YS, Ko PJ, Hsu LA, Chen CF, Yang CW, Hsu TS, Pang $\mathrm{JH}$ : Thrombosed arteriovenous fistula for hemodialysis access is characterized by a marked inflammatory activity. Kidney Int 2005 68:1312-1319

27. De Marchi S, Cecchin E, Falleti E, Giacomello R, Stel G, Sepiacci G, Bortolotti N, Zanello F, Gonano F, Bartoli E: Long-term effects of erythropoietin therapy on fistula stenosis and plasma concentrations of PDGF and MCP-1 in hemodialysis patients. J Am Soc Nephrol 1997, 8:1147-1156

28. De Marchi S, Falleti E, Giacomello R, Stel G, Cecchin E, Sepiacci G, Bortolotti N, Zanello F, Gonano F, Bartoli E: Risk factors for vascular disease and arteriovenous fistula dysfunction in hemodialysis patients. J Am Soc Nephrol 1996, 7:1169-1177

29. Ikegaya $N$, Yamamoto $T$, Takeshita $A$, Watanabe $T$, Yonemura $K$, Miyaji T, Ohishi K, Furuhashi M, Maruyama Y, Hishida A: Elevated erythropoietin receptor and transforming growth factor-beta1 expression in stenotic arteriovenous fistulae used for hemodialysis. J Am Soc Nephrol 2000, 11:928-935

30. Marrone D, Pertosa G, Simone S, Loverre A, Capobianco C, Cifarelli M, Memoli B, Schena FP, Grandaliano G: Local activation of interleukin 6 signaling is associated with arteriovenous fistula stenosis in hemodialysis patients. Am J Kidney Dis 2007, 49:664-673

31. Roy-Chaudhury P, Arend L, Zhang J, Krishnamoorthy M, Wang $Y$ Banerjee R, Samaha A, Munda R: Neointimal hyperplasia in early arteriovenous fistula failure. Am J Kidney Dis 2007, 50:782-790

32. Stracke S, Konner K, Kostlin I, Friedl R, Jehle PM, Hombach V, Keller F, Waltenberger J: Increased expression of TGF-beta1 and IGF-I in inflammatory stenotic lesions of hemodialysis fistulas. Kidney Int 2002, 61:1011-1019

33. Harrison DG, Widder J, Grumbach I, Chen W, Weber M, Searles C Endothelial mechanotransduction, nitric oxide and vascular inflammation. J Intern Med 2006, 259:351-363

34. Lehoux S, Castier Y, Tedgui A: Molecular mechanisms of the vascular responses to haemodynamic forces. J Intern Med 2006, 259:381-392

35. Nam J, Aguda BD, Rath B, Agarwal S: Biomechanical thresholds regulate inflammation through the NF-kappaB pathway: experiments and modeling. PLoS ONE 2009, 4:e5262

36. Gerszten RE, Garcia-Zepeda EA, Lim YC, Yoshida M, Ding HA Gimbrone MA, Jr., Luster AD, Luscinskas FW, Rosenzweig A: MCP-1 and IL-8 trigger firm adhesion of monocytes to vascular endothelium under flow conditions. Nature 1999, 398:718-723

37. Ito T, Ikeda U: Inflammatory cytokines and cardiovascular disease. Curr Drug Targets Inflamm Allergy 2003, 2:257-265

38. Boisvert WA: Modulation of atherogenesis by chemokines. Trends Cardiovasc Med 2004, 14:161-165

39. Ginnan R, Guikema BJ, Halligan KE, Singer HA, Jourd'heuil D: Regulation of smooth muscle by inducible nitric oxide synthase and NADPH oxidase in vascular proliferative diseases. Free Radic Biol Med 2008, 44:1232-1245

40. Barbato JE, Tzeng E: iNOS gene transfer for graft disease. Trends Cardiovasc Med 2004, 14:267-272

41. Kibbe MR, Tzeng E, Gleixner SL, Watkins SC, Kovesdi I, Lizonova A Makaroun MS, Billiar TR, Rhee RY: Adenovirus-mediated gene transfer of human inducible nitric oxide synthase in porcine vein grafts inhibits intimal hyperplasia. J Vasc Surg 2001, 34:156-165

42. Matsuguma K, Ueda S, Yamagishi S, Matsumoto Y, Kaneyuki U, Shibata R, Fujimura T, Matsuoka H, Kimoto M, Kato S, Imaizumi T, Okuda S: Molecular mechanism for elevation of asymmetric dimethylarginine and its role for hypertension in chronic kidney disease. J Am Soc Nephrol 2006, 17:2176-2183

43. Boon RA, Horrevoets AJ: Key transcriptional regulators of the vasoprotective effects of shear stress. Hamostaseologie 2009, 29:39-40, 41-33

44. Davies PF: Hemodynamic shear stress and the endothelium in cardiovascular pathophysiology. Nat Clin Pract Cardiovasc Med 2009, 6:16-26

45. Lam CF, Peterson TE, Richardson DM, Croatt AJ, d'Uscio LV, Nath KA, Katusic ZS: Increased blood flow causes coordinated upregulation of arterial eNOS and biosynthesis of tetrahydrobiopterin. Am J Physiol Heart Circ Physiol 2006, 290:H786-H793

46. Castier Y, Brandes RP, Leseche G, Tedgui A, Lehoux S: p47phoxdependent NADPH oxidase regulates flow-induced vascular remodeling. Circ Res 2005, 97:533-540

47. Tronc F, Wassef M, Esposito B, Henrion D, Glagov S, Tedgui A: Role of $\mathrm{NO}$ in flow-induced remodeling of the rabbit common carotid artery. Arterioscler Thromb Vasc Biol 1996, 16:1256-1262 
48. Mattsson EJ, Geary RL, Kraiss LW, Vergel S, Liao JK, Corson MA, Au YP, Hanson SR, Clowes AW: Is smooth muscle growth in primate arteries regulated by endothelial nitric oxide synthase? J Vasc Surg 1998, 28:514-521

49. O'Riordan E, Mendelev N, Patschan S, Patschan D, Eskander J, Cohen-Gould L, Chander P, Goligorsky MS: Chronic NOS inhibition actuates endothelial-mesenchymal transformation. Am J Physiol Heart Circ Physiol 2007, 292:H285-H294

50. Rekhter M, Nicholls S, Ferguson M, Gordon D: Cell proliferation in human arteriovenous fistulas used for hemodialysis. Arterioscler Thromb 1993, 13:609-617

51. Hayakawa Y, Takemura G, Misao J, Kanoh M, Ohno M, Ohashi H, Takatsu H, Ito H, Fukuda K, Fujiwara T, Minatoguchi S, Fujiwara H: Apoptosis and overexpression of bax protein and bax mRNA in smooth muscle cells within intimal hyperplasia of human radial arteries : analysis with arteriovenous fistulas used for hemodialysis. Arterioscler Thromb Vasc Biol 1999, 19:2066-2077

52. Wu CC, Wen SC, Yang CW, Pu SY, Tsai KC, Chen JW: Plasma ADMA predicts restenosis of arteriovenous fistula. J Am Soc Nephrol 2009, 20:213-222

53. Misra S, Fu AA, Anderson JL, Sethi S, Glockner JF, McKusick MA Bjarnason H, Woodrum DA, Mukhopadhyay D: The rat femoral arteriovenous fistula model: increased expression of matrix metalloproteinase-2 and -9 at the venous stenosis. J Vasc Interv Radiol 2008, 19:587-594

54. Pascarella L, Schmid-Schonbein GW, Bergan J: An animal model of venous hypertension: the role of inflammation in venous valve failure. J Vasc Surg 2005, 41:303-311 